Journal of Transport and Land Use 2:1 (Fall 2008) pp. 153-182

Available at http://jtlu.org

\title{
Equity impacts of transportation improvements on core and peripheral cities
}

\author{
Eran Leck \\ Technion-Israel Institute of Technology \\ Shlomo Bekhor \\ Technion-Israel Institute of Technology $b$ \\ Daniel Gat \\ Technion-Israel Institute of Technology
}

\begin{abstract}
This paper assesses the short-term impact of transportation improvements on the reduction of socio-economic disparities between core and peripheral cities using data extracted from the 1995 Israel Census. The methodology applied in the study estimates discrete choice models in order to identify key variables affecting commuting decisions. Policy simulations are employed to illustrate the effect of diminishing spatial friction on wage convergence between poor southern towns and affluent core cities. The empirical evidence suggests that transportation improvements, especially in the form of introducing new rail links in underserved cities, could significantly contribute to the alleviation of spatial wage disparities between core and peripheral cities.
\end{abstract}

Keywords: Transportation improvements; Economic equity; Wage disparities; Discrete choice.

\section{Introduction}

Recent years have seen a growing interest in the mechanisms linking a barrier-free geography and economic efficiency and equity. A common claim made by many urban economists, regional planners and transportation scientists is that transportation improvements extend the borders of isolated labor markets, thus contributing to enhanced welfare by widening the scope of opportunities for disadvantaged communities (Rietveld 1989; Garrison 1994, Banister and Lichfield 1995; Fox 2001).

\footnotetext{
${ }^{a}$ leck@tx.technion.ac.il

${ }^{b}$ sbekhor@tx.technion.ac.il

c'dangat@bezeqint.net
}

Copyright 2008 Eran Leck, Shlomo Bekhor, and Daniel Gat.

Licensed under the Creative Commons Attribution - NonCommercial License 3.0. 
Equity is concerned with the spatial distribution of income and resources, and is inevitably linked to concepts of fairness and social justice. During the past four decades, much research has been conducted to better understand the linkage between welfare optimization and the spatial movement of the labor force. Much of this research has focused on inter-regional migration as a function of workplace and residence optimization decisions (Lansing and Mueller 1967; De Jong and Fawcet 1981; Massey et al. 1994).

A review of the literature reveals relatively few modeling frameworks that address the transportation-equity nexus — and even these do so only partially (Waddell 2000; Justman and Spivak 2004; Hazans 2004). This stands in contrast to the voluminous research activity conducted over the last two decades on the efficiency impacts of transportation improvements (e.g. Aschauer 1989; Munnell 1990; Fritsch and Prud'homme 1995).

The research presented in this paper was motivated by the need to provide theoretical and empirical underpinnings for the short-term effects of transportation improvements on the generation of economic equity benefits. The theoretical motive is derived from the relative absence of models and theoretical frameworks dealing with the interface between spatial equity and transportation. The growing disparities between Israel's core and peripheral regions constitute the empirical motive.

To address the transportation-equity nexus, this paper poses the following research questions: Can transportation improvements generate tangible short-term welfare economic benefits, such as wage convergence between core and periphery? And if so, what will be the short-term contribution of such improvements to the economic welfare of the study region?

In this paper, a three-part methodology is used to address these questions. First, we determine how transportation contributes to a peripheral region's potential for economic equity with the core. Second, we investigate this contribution using mathematical tools based on disaggregate models. Third, we apply these tools to a study region and carry out policy simulations.

\section{Prior research}

The term "equity" refers to the distribution of resources which affect people's opportunities and quality of life. This issue was first researched in the 1950s and 1960s, when new theories about the links between economic growth, income distribution and inequality began to emerge.

One of the most notable theories was the path-breaking work of Kuznets (1955), who argued that there is a trade-off between reducing inequality and promoting growth. Kuznets' theory, best known as the Kuznets Hypothesis, suggests that the curve for income inequality traces an inverted- $U$ shape through the economic development pro- 
cess. In early stages of development, the concentration of income-generating wealth in the hands of a group of individuals is seen as a required condition for the accumulation of capital that fuels economic growth. In later stages of development, the benefits of growth are passed on to other members of society as higher wages and increased incomes. The growth of personal income inequality then begins to slow, and income inequality eventually diminishes.

Williamson (1965) was one of the first economists to tie the spatial dimension to Kuznets' inverted- $U$ curve and to the issue of unequal regional development. Attributing the initial concentrations of income in certain geographic regions to unequal natural resource endowments, he argued that these concentrations attracted selective skilled labor migration from peripheral regions and generated rapid income growth in core regions. This resulted in widening differentials in per-capita incomes between core and peripheral regions. Williamson's model shows that, over time, a diffusion of income-generating factors leads to a decline in inequality and to a process of convergence, in which poor economies catch up with rich ones at either the regional or the international level (Rey 2001).

Myrdal (1957) outlined a schema similar to the one proposed by Kuznets and Williamson, suggesting that initial divergence among regions is followed by convergence. He maintained that market forces tend to widen interregional differences in factor income, causing rich regions to grow richer and poor regions to grow poorer. Myrdal claimed that certain factors can mitigate interregional wage disparities, and accentuated the role of the "welfare state" in reducing these differences and in contributing to income convergence. Investments in education, communications and especially in transportation were seen by him as forces that "strengthen the centrifugal spread of economic expansion."

Many studies, especially in recent years, have focused on links between transportation and equity. These studies have dealt with a wide range of equity issues such as the ability of various social groups (e.g. the poor, women, minorities, the elderly) to access goods, services (health care, public transit, etc.) and destinations (jobs, education centers, recreational activities, etc.).

Pickup and Giuliano (2005) investigated the connection between transport and social exclusion in Europe and the United States. Their research shows that the dominance of the private vehicle and the lack of good public transportation in urban areas in the United States exclude various social groups (such as immigrants, single mothers, and a large part of the African American population concentrated in inner cities) from pursuing employment opportunities that are available to car users. Dobbs (2005) shows in her research, conducted in England, that a woman's access to a car is often the most significant factor in her ability to obtain a job. The study indicates that in automobile-dependent areas, car access helps women achieve equity objectives such as economic opportunity and social independence. Jia and Wachs' (1998) study on 
parking and affordable housing in six San Francisco neighborhoods shows that high parking costs reduce housing affordability for lower and middle income households, preventing them from purchasing houses in these communities. Pucher and Renne (2003) report in their study on the accessibility of various socio-economic groups to rail service that rich suburban commuters use rail three times more than the poor. Their research provokes an important equity question. They show in their analysis that the poor subsidize the rich because the latter group makes longer trips (transit fares have a fixed rate regardless of distance).

Despite the many studies which have probed the linkage between equity and spatial impedance, a review of the regional science and economic literature reveals relatively few modeling frameworks that address this connection. Justman and Spivak (2004) present a theoretical model of two cities that highlights the association between migration and equity. They attribute the variations in the socio-economic level of cities to economic conditions such as agglomeration and economies of scale, the quality of the education system, and the presence of a migration process. The migration in their model partially reacts to difference in the level of education, wages, housing prices and local infrastructure. The authors did not intervene in the proximity parameter, assuming it to be a geographic constant. Conceptually, however, transportation policy could be included in their model by substituting travel time for distance.

Work by Fujita and Mori (1996) on the aspects of transport nodes in the process of spatial economic development supplies interesting insights regarding the role of transport improvements in mitigating spatial-economic disparities. The authors question the centrifugal role of transport improvements. Using a theoretical model, they show that in order to promote economic growth in an economy characterized by a coreperiphery dualism, it is not always helpful to immediately improve transport connections between the two regions. Their findings demonstrate that if the periphery does not possess a comparative advantage, transportation improvements will simply help to intensify the market competition for industrial products in the periphery; hence, transportation improvements may even cause the loss of industries in the periphery and draw the skilled labor force (by migration) to the core. Fujita and Mori conclude that "in such a situation, a temporary protection of industries in the periphery by worsening the transport connection for a short period of time may be desirable."

In recent years, emphasis within the regional and spatial economic literature has shifted towards modeling the factors influencing commuting decisions. Contrary to their sister migration models - in which spatial movement of the labor force is understood mainly as a function of demographic (e.g. age, ethnic background), social (e.g. presence of family or friends at destination) and economic (offered wage at destination, employment opportunities, etc.) factors-commuting models also emphasize the role of spatial friction in attracting workers to a particular commuting destination.

An interesting and novel point of view on the linkage between spatial equity and 
commuting is provided in Hazans' (2004) study on the Baltic States. Hazans hypothesized that commuting reduces welfare disparities between the capital cities and rural areas of Estonia, Latvia and Lithuania; by estimating two sets of earnings functions with location variables measured at workplace and residence ends, he was able to validate this hypothesis. His results indicate that, in Estonia and Latvia, commuting substantially reduces wage differentials between capital cities and rural areas, as well as between capital cities and other cities. However, Hazans did not include a transportation component (such as accessibility level or travel time) in his model.

An aggregated log-linear regression model by Renkow and Hoover (2000) tried to capture the simultaneity of workplace and residential choice in North Carolina (USA). The authors found that cross-county differences in wages, travel distance, and housing costs are the most important factors in affecting commuting choices. Presman and Arnon (2006) report similar results in an aggregated gravity model set to estimate the scope of commuting patterns at the sub-district level in Israel. Higher offered-wage rates were identified as a key variable affecting commuting flows. The main weaknesses of Renkow and Hoover's model is the aggregate level of analysis and the use of distance instead of travel time. The authors themselves note that the "optimal variable for measuring accessibility is commuting time, but it is not feasible for computation in the district level."

The economic studies mentioned above supply valuable insights regarding the social and economic mechanisms influencing commuting choices. However, these studies' high level of aggregation and the models' use of distance rather than travel time makes it very difficult to estimate the effect of diminishing spatial friction on equity measures such as regional income convergence. In this context, spatial choice and spatial interaction models offer a variety of tools.

Spatial choice and spatial interaction models are one of the most commonly applied modeling frameworks in geographic, transportation, and regional science studies (see Baxter and Ewing 1981; Mayhew et al. 1986; Fotheringham and O'Kelly 1989). These models are used to explain a variety of urban activities such as residential and work choices, journey-to-school trips, and shopping trips (Roy and Thill 2004). Spatial choice models also constitute a powerful tool for conducting policy simulations on various issues relating to the urban arena. Such models may forecast urban growth, predict future decentralization of population and industry at a spatially detailed level, or simulate the impacts of transportation investments on job growth, housing and retail markets, and land-use policy (see for example Wegener et al. 1991; Landis 1995; Banister and Berechman 2001).

The spatial choice framework is expanded in the following section of this paper to reflect the effect of transport improvements on welfare issues relating to the alleviation of spatial socio-economic disparities. 


\section{Methodology}

\subsection{Conceptual Framework}

This section outlines the conceptual framework for investigating the effects of transportation improvements on socio-economic equity (Figure 1).

Figure 1: Contribution of transportation improvements to the promotion of efficiency.

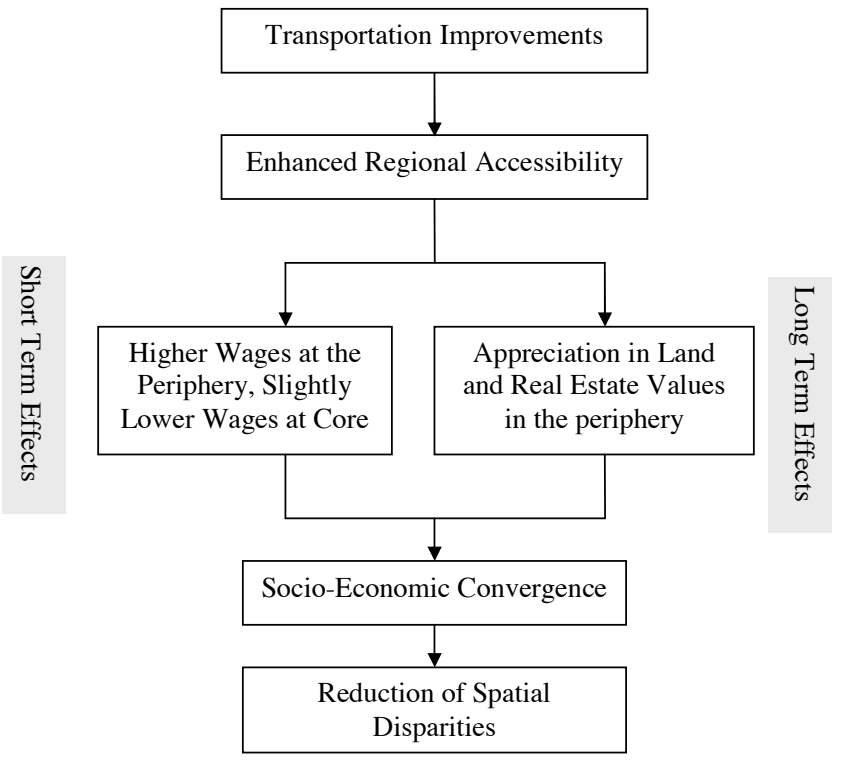

The most important feature of transportation infrastructure improvements, with regard to the regional equity issue, is the reduction of spatial friction, which leads to enhanced regional accessibility. Higher regional accessibility extends the borders of the labor market, allowing people who live in the periphery to work in core regions and enjoy the higher wages offered there. The resulting larger supply of labor may slightly lower the wages of people who live in the core. Enhanced regional accessibility may also contribute, in the long term, to the appreciation of assets and land values in peripheral regions. Higher wages and the appreciation of land values in the periphery may, finally, lead to a process of convergence and gap reduction between peripheral and core regions, and attract new residents and firms to the periphery.

The conceptual framework presented above highlights the role of transport improvements in contributing to short-term and long-term equity benefits. This paper only focuses on the short-term implications of transport improvements. We assume 
that in the short-term transport improvements do not contribute to significant physical capital and land-use changes (e.g. construction of new manufacturing facilities, addition of office space, etc.). Land value impacts, considered in the scope of this paper as long-term effects, are therefore not covered.

In order to address these short-term impacts, we propose a set of empirical models, with the main aim of estimating and forecasting the contribution of transportation improvements to the enhancement of economic equity in an $n$-city system. The models demonstrate how an enhanced commuting pattern may lead individuals to change their work location in favor of cities that offer higher wages and other amenities. The welfare-gain mechanism in the models is defined as income growth in peripheral cities, or alternately as income convergence between peripheral towns and core cities.

\subsection{Study area}

The study area (Figure 2) encompasses 101 cities in Israel with populations of more than 2,000 residents. We are particularly interested in two regions: the core region of central Israel (the Tel Aviv metropolitan area) and the Near Negev (the greater Beersheba region) in the southern part of the country.

These two regions present an acute socio-economic contrast. The core region, which includes Tel Aviv and its surrounding satellites, is socio-economically successful and draws the best businesses and the most skilled workforce. It suffers from typical "rich-man's problems" plaguing central areas: traffic congestion, demographic problems, and environmental pressures (Gat 2004). The southern periphery comprises one central city (Beersheba), Jewish so-called "development towns" (which hardly develop), Arab Bedouin official towns, and unrecognized dispersed small communities. It continuously suffers from severe "poor man's problems": chronic unemployment, low-quality education, and a shortage of skilled workers. The socioeconomic background of the development towns' residents has contributed to the transformation of these towns into conspicuous pockets of deprivation and poverty (Yiftachel 2000).

The Near Negev is made up of the city of Beersheba, which is surrounded by several small Jewish communities (Sderot, Netivot, Ofaqim, Arad, Dimona, Yeruham) and Arab Bedouin towns (Rahat, Tel Sheva, Aroer, and dozens of dispersed settlements) that are poorly connected to each other. Due to their low residential and employment densities, these towns lack the scale economics necessary for creating producer and consumer amenities. Statistical data show considerable differences between the southern peripheral towns and the core region cities, in almost all socio-economic parameters. These disparities are reflected in wage variations: in the year 2000, 44-55 percent of employees in the southern towns earned a salary equal to or less than the minimum wage, while only 24-32 percent of employees in the core region cities in Central Israel earned a similarly low salary. (Social-Security Institute 2002). 
Figure 2: Study area.

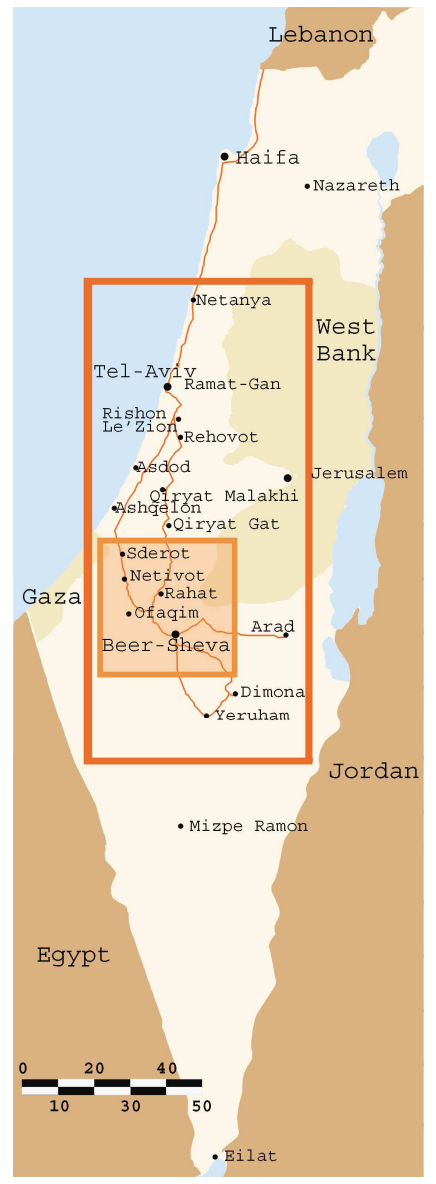

\subsection{Data acquisition}

In order to address the research questions posed, it was necessary to collect data from various sources. Four main data sources were used in the formulation of a combined master database: city characteristics data, Census of Population and Housing, housing price data, and travel time data. The data sources are briefly described in the following paragraphs.

The aggregated city characteristics data was extracted from the "Local Authorities Files," published electronically on the Israel Central Bureau of Statistics (CBS) website (CBS, 2000). This cross-sectional data source for more than 200 localities covers various themes such as demographic characteristics and measures of socio-economic 
well-being (e.g. population, number of dwellings, residential density and the socioeconomic cluster of the city), as well as other topics such as construction, transport and infrastructure.

Socio-economic and labor-force data were collected from the 20 percent sample of the 1995 Israel Census of Population and Housing. This detailed, disaggregated database supplies information on the social and demographic characteristics of the population. The data used from this source include demographic, geographic, employment and land use variables.

The raw sample supplied by the CBS included 1,113,420 records. Since the model focuses on the labor market, individuals not belonging to the civilian workforce (e.g. children under the age of 15) or do not work were removed from the sample. Out of the remaining records of working individuals, additional records were filtered out due to "unknown income" or reported "zero income." Due to CBS confidentiality concerns, city residence and workplace codes are only reported for cities above 2,000 inhabitants. In addition to this restriction, a significant number of individuals did not report their place of work; records for which it was impossible to match an employees place of residence to their place of work were also removed. Out of the remaining observations, a few more cases were removed due to various reasons (e.g. missing values in key variables such occupation; small towns that had no matching aggregated city characteristics data etc.). The final disaggregated Census dataset used in this study includes a total of 211,230 observations.

The housing price data were obtained from two sources: an administrative dataset supplied by the Ministry of Construction and Housing (2006); and an independent survey based on a sample of real-estate Internet sites. The dataset includes data on the number of transactions in each city, nominal and real prices per square meter in New Israeli Shekels (NIS), prices per room in NIS, and prices per apartment in NIS.

Travel time data for different modes (automobile, bus, train) were extracted from national travel time matrices prepared for the Israel Ministry of Transport (A.B. Plan 2004). These matrices were obtained from traffic assignment model outputs for A.M. peak hour demand matrices for the year 2003. Representative travel times between cities were calculated by extracting the centroid of each city polygon and computing the respective times between two centroids. For the purposes of this paper, it is safe to assume that the travel time data represent the magnitude of the spatial friction between the cities.

The three aggregated datasets (city characteristics, housing price, travel time) were merged into the refined disaggregated census dataset. Given the limitations of the data, certain assumptions were made for this specific study. The model assumes full employment in a "closed-city" system. This assumption, fairly common in economic models, means that all workers are employed and may offer their labor services only in cities which belong to the choice set. In addition, no work is possible outside the 
system (e.g. abroad).

\section{Model Specification}

The equity model is estimated using the multinomial logit (MNL) model formulation (Ben Akiva and Lerman, 1985). The MNL model assumes that decision maker $n$ faces discrete alternatives $j=1, \ldots, J$ and chooses the alternative that maximizes utility. The utility is assumed to be a combination of observed and unobserved factors. The dependent variable in the model is the choice of workplace (city). The general form of the systematic utility $V_{i n}$ and the choice probability Pin of the MNL model are given by the following equations:

$$
\begin{gathered}
V_{i n}=\beta_{1} x_{1 i n}+\beta_{2} x_{2 i n}+L+\beta_{k} x_{k i n} \\
P_{i n}=\frac{e^{V_{i n}}}{\sum_{J \in C_{n}} e^{V_{j n}}}
\end{gathered}
$$

Where:

$V_{i n}=$ Systematic (observed) utility of alternative $i$ for individual $n . X_{k i n}=$ Attribute $k$ of alternative $i$ for individual $n$.

$C_{n}=$ Set of available alternatives to individual $n$.

Several utility specifications were tested and are detailed in the next section.

\subsection{Attainment of equity indicator}

As been previously discussed in the literature review section, equity can be defined in various ways, and different indicators can be used to describe it. We use the average wage in the origin (city of residence) as a proxy for the economic welfare of its residents. Figure 3 schematically describes the process by which the labor and wage vectors are attained in the model.

Following the estimation of the parameters by the disaggregated MNL model, the utility of selecting a residence/work-city combination $V_{i j}$ (there are $i \times j$ combinations) is calculated by multiplying the estimated parameters $(\beta)$ by the independent variable (IV) vectors. The division of a particular $V_{i j}$ by the sum of utility $V_{i j}$ $(j=1, \ldots, n)$ yields the probability of selecting a particular residence/work-city combination $\left(P_{i j}\right)$. Multiplication of this probability by the number of employed workforce in city $i\left(E_{i}\right)$ equals to the expected number of employees living in city $i$ and working in city $j\left(E_{i j}\right)$. The product of $E_{i j}$ and the average wage of employed persons residing in city $i$ and working in city $j\left(\bar{w}_{i j}\right)$ produces the expected total payroll of employed 
Figure 3: Attainment of equity indicator in the model.

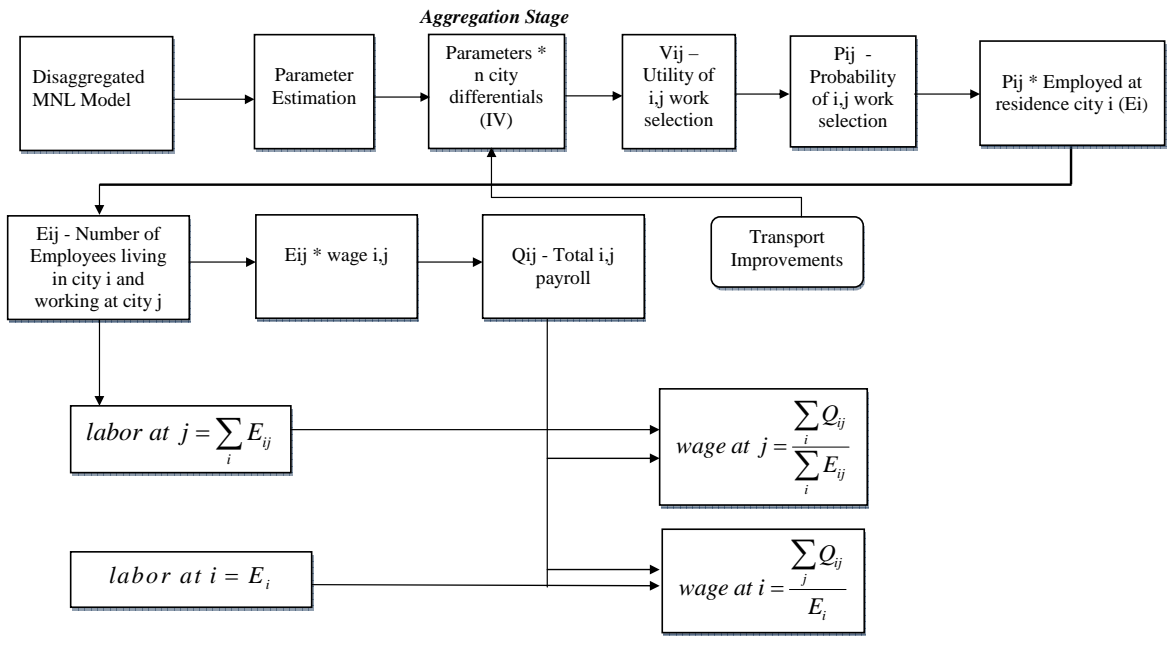

individuals living in residence city $i$ and working in city $j\left(Q_{i j}\right)$. The average wage at $i$ (average wage of individuals who reside in a particular city) is obtained by:

$$
\bar{w}_{i}=\frac{\sum_{j} Q_{i j}}{E_{i}}
$$

The wage at $i\left(\bar{w}_{i}\right)$ represents the equity indicator in the model. The higher it is, the greater the welfare in a particular city. When transportation improvements are made (see red box) and travel time is consequently reduced, the estimated spatial impedance coefficient is multiplied by the new travel time differentials. This changes the utility, and consequently the probability of selecting a work city $j$ by residents of city $i$. Due to these changes, new wage vectors are created at $i$, and consequently new equity measures are attained.

\section{Research findings}

Table 1 presents a summary of average offered wages and number of employees (proxy to the number of jobs) at work destination in selected study-region cities. As can be seen from the table, there are clear differences (17-26 percent) in the proposed wages between Beersheba and its surrounding satellite towns. The wage disparity between these towns and Tel Aviv is almost double, ranging from 39 percent in the case of Ra- 
hat to 50 in the case of Netivot. Although Rahat is one of the poorest Arab Bedouin towns in Israel, the average offered wage there is higher than in some of the Jewish towns. This is due to the fact that most of the (few) available jobs in Rahat are in the public sector (teachers, municipal workers, etc.). There are much smaller wage disparities between towns in the Beersheba metropolitan area and towns and other southern cities (e.g. Ashdod, Ashqelon, Qiryat Gat), located north of the greater Beersheba area and south of the Tel Aviv metropolitan area. Another notable difference between the southern periphery and core region cities is in the number of job opportunities: the Tel Aviv metropolitan area offers more than ten times more jobs than the Beersheba metropolitan area.

Table 1: Offered wages and jobs in selected cities.

\begin{tabular}{|c|c|c|c|}
\hline & $\begin{array}{l}\text { Number } \\
\text { of Cities }\end{array}$ & $\begin{array}{l}\text { Average Offered } \\
\text { Monthly Wage in } \\
1995 \text { NIS* }\end{array}$ & $\begin{array}{l}\text { Number of } \\
\text { Employees (Jobs) at } \\
\text { Work Destination }\end{array}$ \\
\hline Beersheba & 1 & 3,547 & 44,740 \\
\hline Netivot (Jewish) & 1 & 2,809 & 2,840 \\
\hline Ofaqim (Jewish) & 1 & 2,882 & 2,975 \\
\hline Rahat (Arab Bedouin) & 1 & 3,029 & 830 \\
\hline Sderot (Jewish) & 1 & 2,855 & 4,315 \\
\hline Other cities in Beersheba & 8 & 3,161 & 15,960 \\
\hline Metro & & & \\
\hline Total Beersheba Metro Area & 13 & 3,556 & 71,660 \\
\hline $\begin{array}{l}\text { Southern Cities not part of } \\
\text { Beersheba Metro Area }\end{array}$ & 6 & 3,359 & 63,540 \\
\hline Tel Aviv (Jewish) & 1 & 4,215 & 266,985 \\
\hline Core cities & 30 & 3,691 & 460,460 \\
\hline
\end{tabular}

${ }^{*}$ In 1995, 1 US\$ = 3.5 New Israeli Shekels (NIS)

Table 2 presents a travel time matrix that shows auto trip lengths (in minutes) during A.M. peak hours between selected cities in the Beersheba metropolitan area and Tel Aviv. As can be seen from the table, trip lengths between Beersheba and its surrounding satellite towns range between 27 and 44 minutes, whereas trips lengths between the various Beersheba metropolitan area towns and Tel Aviv are in the 65-111 minute range.

\subsection{Model variables}

Prior to presenting the results of the models, we will briefly describe their structure and the variables used in the analysis. This section is divided into two parts: Regional models and National models. The main aim of the regional models is to emphasize 
Table 2: A.M. peak hours auto travel time matrix (2000) in minutes - selected cities.

\begin{tabular}{lcccccc}
\hline & \multicolumn{6}{c}{ Destination } \\
\cline { 2 - 7 } Origin & Arad & Beersheba & Netivot & Ofaqim & Sderot & Tel Aviv \\
\hline Arad & - & 44 & 64 & 64 & 65 & 111 \\
Beersheba & 44 & - & 31 & 27 & 39 & 90 \\
Netivot & 67 & 31 & - & 18 & 13 & 71 \\
Ofaqim & 66 & 28 & 19 & - & 27 & 86 \\
Sderot & 69 & 39 & 13 & 27 & - & 65 \\
Tel Aviv & 110 & 88 & 67 & 81 & 61 & - \\
\hline
\end{tabular}

the differences between various groups of commuters in the greater Beersheba region, giving particular attention to variations in the ethnic and educational background of the commuting population, as well as to gender-based differences which were identified in the literature as key determinants of commuting behavior. The national model encompasses all cities with a population of more than 2,000 residents, and serves as a basis for the application and simulation stage reported in the final section of this paper. The coefficient estimates of the regional models cannot be used in the simulation stage, because they might lead to biased and skewed results.

The regional commuting models use a large number of variables to explain the workplace decisions of Beersheba metropolitan area residents. 1. In addition to and on the basis of the raw variables described in the data acquisition section, new variables and indices were developed. These variables cover personal attributes of commuters as well as aggregated characteristics of the work city.

Aggregated city-characteristics variables include the population size of the city, dummy variables for small cities, socio-economic cluster ranking, total business floor area and total number of employees. Building on existing travel time variables (auto, bus and train travel time between cities) a composite utility index (CUI) reflecting the combined (ln-sum) effect of the three modes of travel was formulated as:

$$
\mathrm{CUI}=\ln \left(e^{\beta_{1} \times \text { Autott }}+e^{\beta_{2} \times \text { Bustt }}+e^{\beta_{3} \times \text { Traintt }}\right)
$$

The CUI is similar to composite impedance methods used in trip distribution models to account for the availability of alternative modes. The theory underlying composite utilities (Allen, 1984) suggests that destinations become more attractive when there is an improvement of the level of service in any of the available modes between the origin and destination.

\footnotetext{
${ }^{1}$ The data sources for these variables were covered in detail in the data acquisition section.
} 
The coefficient estimates (a flat value of -0.04 for the auto, bus, and train modes) for the CUI were taken from the NTA transportation planning model (PGL 2001). This index makes it possible to identify the effect of a particular mode on potential outcome (the dependent variable), when the values of the other modes are held constant.

Personal attributes include demographic variables such as dummy variables for age groups, a dummy for female workers, and a dummy variable for Jews of Northern African or Asian decent; socio-economic variables include income, years of schooling, a dummy for unskilled workers, and a dummy for academic profession. Other variables associated with the decision maker include dummies for work in Tel Aviv and in Arab Bedouin cities. Because these variables represent the personal characteristics of the decision maker on the residence side, they were interacted with an aggregated variable (aerial distance between cities) to produce variance between the models' alternatives; this technique is derived from destination choice models estimated in the transportation literature (e.g. Bekhor and Prashker 2007).

The merged dataset served as the basis for constructing the sample for the regional commuting models. This sample represents commuters who reside in 16 cities in the Beersheba metropolitan area (including Jewish and Arab Bedouin towns) and have 64 work alternatives (in the Beersheba and Tel Aviv metropolitan areas, and in Jerusalem). A total of 10,795 relevant records reflecting this particular residence-work combination were identified and extracted from the merged dataset.

\subsection{Estimated models}

\section{Regional models}

Estimation results for the regional models are presented in Tables 3, 4, and 5. Table 3 reports the results for a set of three models, comprising one full model and two submodels segmented by the educational status (academic and non-academic professions) of the commuting population. The full model shows a high fit (Pseudo $R^{2}$ of 0.77 ). The strongest predictors of work city choice are employment differentials and composite utility differentials. The coefficients of these two variables are positive, suggesting that a high composite utility (analagous to short travel time) between cities and a large job supply contribute to the probability of selecting a particular work city. When the two segmented models are compared to each other, it is noticeable that commuters who belong to the "non-academic professionals" subset are more sensitive to the composite utility (more reluctant to work at distant locations). This might be explained in two ways: first, unskilled workers are generally less mobile than highly skilled workers and the geographical scope of their employment opportunities is more limited (see for example McCormick 1997); second, there is no incentive for unskilled workers to search for low-paying/low-skilled jobs in distant locations, as such jobs are present in 
their home towns.

Small-city dummy variables also emerge as strong predictors of work-city selection. The coefficients of these variables are negative, suggesting that small cities contribute to disutility in the selection process. It is evident from the estimation results that the smaller the city is, the larger the disutility effect. As can be seen from the table, older persons are less prone to choose distant work locations. There is also a high disutility associated with selecting an Arab Bedouin city as a place a work; this is mainly due to the low supply of jobs in these cities, but may also be a result of the cultural, ethnical and linguistic barriers separating the Jewish and non-Jewish populations in the Northern Negev. As can be seen from the segmented models, there is a significant difference in the parameter estimates of the Arab Bedouin city dummy. The disutility of selecting an Arab Bedouin city as a place a work is much lower among commuters who belong to the "academic professionals" subset. This observation is explained by the fact that the majority of jobs offered in Arab Bedouin cities are in the public sector (especially teachers), which is characterized by the relatively high educational level of its employees.

In order to test statistically whether the combined likelihood of the two segmented models is greater than that of the full (not segmented) model, the following loglikelihood ratio test was constructed:

$$
\begin{aligned}
-2\{L(\text { Full })- & {[L(\text { Academic })+L(\text { Non-Academic })]\} } \\
& \sim \chi^{2}\{[d f(\text { Academic })+d f(\text { Non-Academic })]-d f(\text { Full })\}
\end{aligned}
$$

The likelihood ratio for the test is 134 , which is higher than the $\chi^{2}$ value (34.5) corresponding to 13 degrees of freedom $(14+14-15$ estimated parameters) and a significance level of 0.001 . Therefore, the null hypothesis regarding no differences in the likelihoods of the full and combined segmented models is rejected. The separation of the full model into two models indeed enhances the ability of explaining workplace selections.

Table 4 presents a set of two models segmented by the type of locality (Jewish or Arab Bedouin). As can be seen in the table, the number of work-city alternatives in the segmented Jewish locality model is smaller (54) than in the segmented Arab Bedouin locality model (64). This specific formulation is due to initial data analysis findings that indicated that only 0.4 percent of employed individuals who live in Jewish Beersheba metropolitan area cities work in Arab Bedouin towns, whereas approximately 56 percent of workers who reside in Arab Bedouin towns situated in the Beersheba metropolitan area work in Jewish towns.

The estimation results reported in Table 4 show that residents of Jewish localities are 


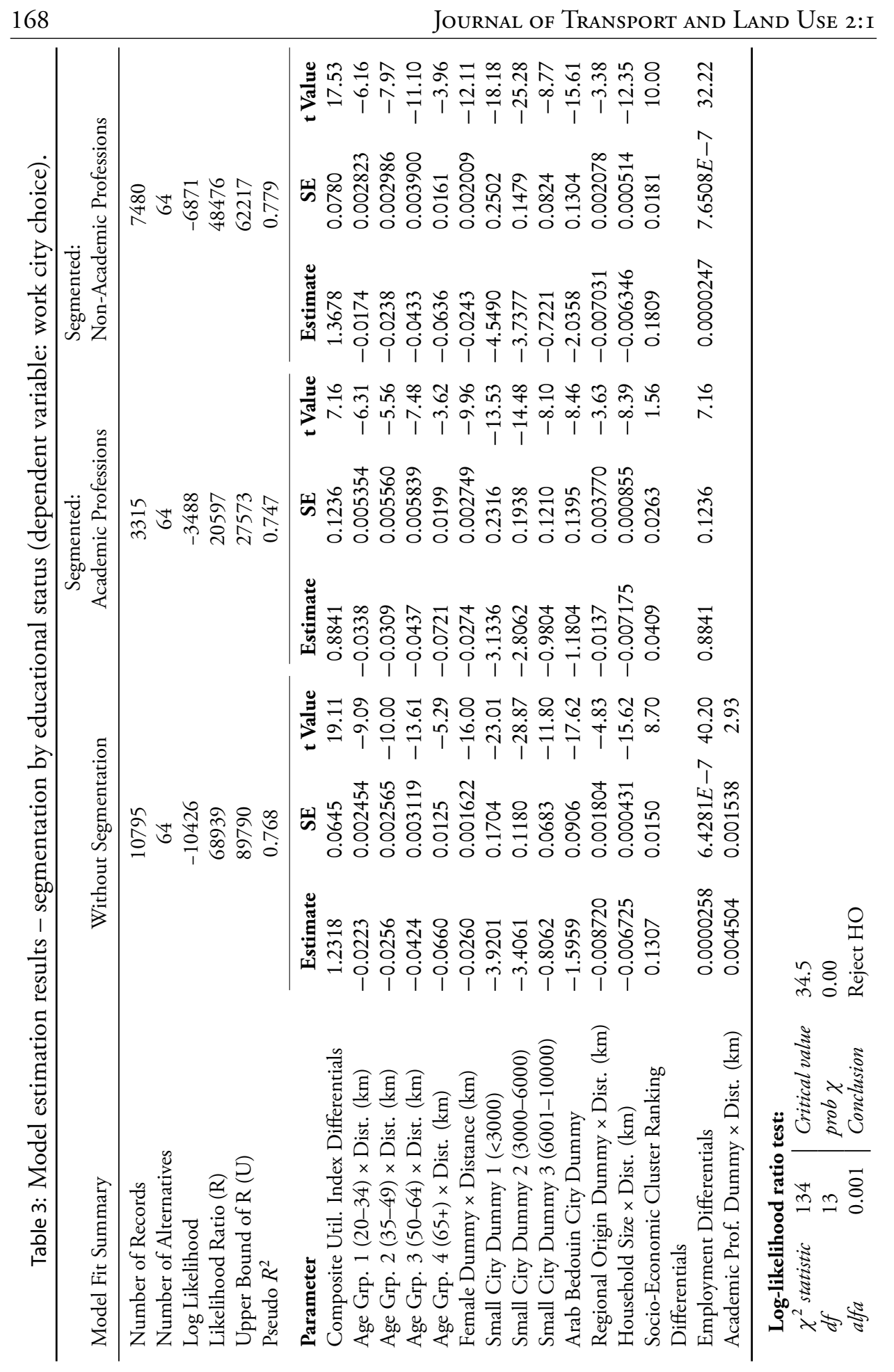


more sensitive than residents of Arab Bedouin towns to the composite utility variable. This finding further supports the results of the former model, because it highlights the lack of employment opportunities in Bedouin towns, and the large volume of outcommuting from these towns to Jewish cities.

An interesting variable explaining commuting choice is the interaction variable years-of-schooling $\times$ wage-differentials. As can be seen from the table, this variable is significant for the Jewish localities subset and insignificant for the Bedouin localities subset. A possible explanation for this result may be rooted in the low educational level within the Bedouin population, which denies them the opportunity to compete for jobs in socio-economically viable cities where higher wages are offered. Another notable parameter explaining the workplace selection among residents of the Beersheba metropolitan area is the size variable denoting the log business floor area in square meters. The sign of the coefficient is positive, suggesting that the larger the built-up commercial area in the city, the higher the probability that a commuter will select this city as his or her place of work.

Table 5 reports estimation results for a set models segmented by gender and care for children. This particular segmentation, which departs from the more traditional malefemale analysis, is based on the assumption that the characteristics of young women without children and older women who no longer bear child-care responsibilities are fairly similar to those of men. As can be seen from the table, the high variation in the composite utility index indicates that men and women without children are much more sensitive to travel time changes than younger women with children. This result is explained by the fact that women with child care responsibilities tend to work closer to home and make shorter trips. The findings presented in Table 5 are consistent with the results of many studies that have demonstrated the existence of significant differences between the sexes in travel behavior, and have shown that the disutility of commuting time is particularly high for females with children (e.g. Giuliano 1979; Madden 1981; Pickup 1985; Hanson and Pratt 1990; Rosenbloom and Burns 1993; van den Berg and Gorter 1997).

Another interesting finding arising from an analysis of the parameters in the two segmented models is the difference in the sign of the monthly wage differentials. In the subset containing males and women with no children, the sign of the coefficient is positive, suggesting that a higher offered-wage rate in a particular city attracts workers to that destination. In the model of young women with children, the coefficient sign is negative and significant; this does not necessarily mean that a higher offered-wage rate is a disutility for women, but rather suggests that women's geographical job search environment is more limited. In our particular case, the negative sign of the coefficient can be explained by the combination of two parameters: the low offered-wage rate in towns in the Beersheba metropolitan area, and the inclination of women with children to take jobs in the residence towns. The log-likelihood ratio test, constructed to deter- 


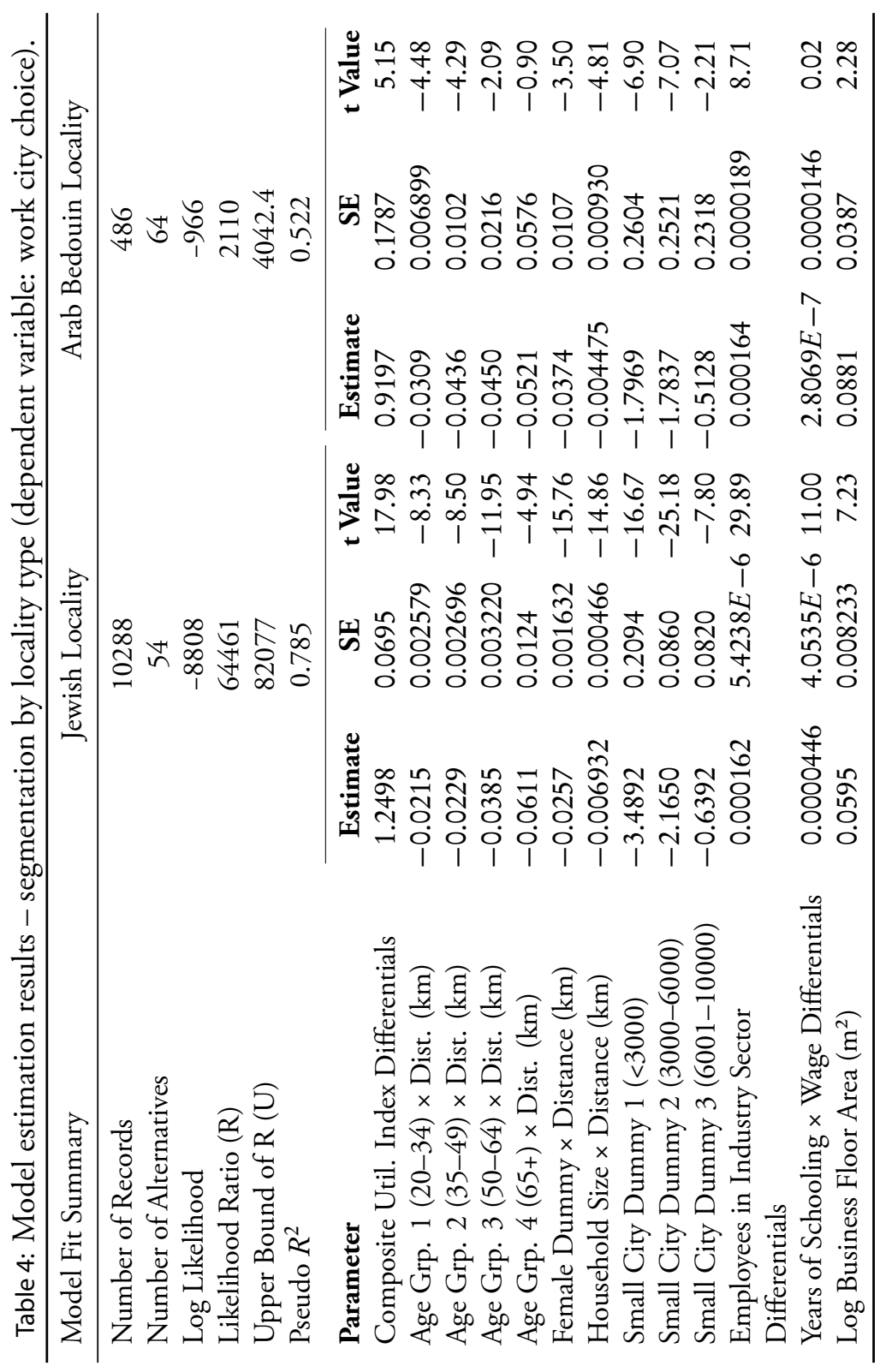




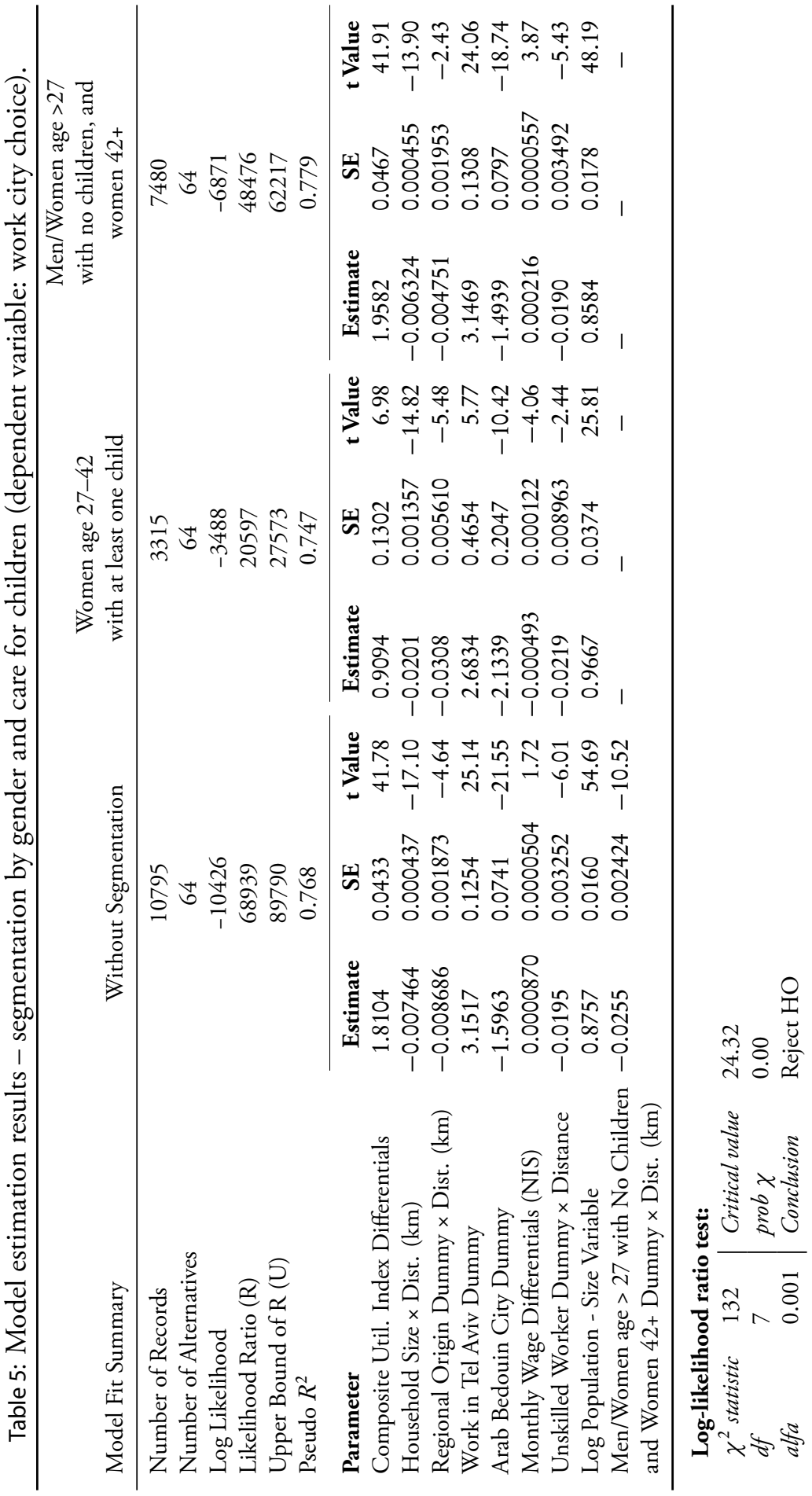


mine whether the combined likelihood of the two segmented models is significantly greater than that of the full model, shows that the segmentation enhances the model's ability to explain workplace selection.

\section{National model}

Table 6 presents the results of the national commuting model, which is the basis for the third stage of this research (application and simulation), reported in the next section. As in the case of the regional models, the national model is based on a representative sample (approximately 20 percent) taken from the merged meta-file. The dataset used for model estimation contains 38,630 records. The variables used in the model are similar to the ones used in the regional models, with the exception of three additional regional city dummy variables (work in Beersheba, Haifa and Ramat Gan) and a dummy for working and residing in the same city. As can be seen from the table, the model shows a fairly high fit (pseudo- $R^{2}$ of 0.64 ) with all variables significant at least at the 0.01 level. It is acknowledged, however, that the model's high t-values are partially due to the large sample size.

Regional dummy variables denoting proximity to large employment hubs such as Haifa (north), Tel Aviv and Ramat-Gan (core), and Beersheba (south) were also found to be key variables in explaining work selection. Note that these four dummy variables are actually interaction variables normalized (multiplied) by distance (values of the variables can be either 0 or $1 \times d i j$ ). The variable that indicates working and residing in the same city was found to be the second strongest variable (after composite utility index) in explaining work city choice. Apartment price per square meter was found to be positive and significant in explaining commuting choices, although its impact (coefficient value) on workplace selection is rather small. In this model, apartment price is a proxy for the economic robustness of the city, and does not function as a "pull or push factor" for working in a particular city, as in the residential choice models where land value is an important variable in explaining residential location choices.

\section{Simulation}

This section illustrates the application of the national model to two hypothetical scenarios purposely chosen to evaluate the impact of different transportation improvements. Two types of simulation scenarios forecasting the impact of transportation improvements on labor and income changes were carried out: the first estimates the impact of auto travel time reduction; the second predicts the effect of linking peripheral towns to the national rail system, based on the future Israel Railways line expansion plan for the year 2010. In the auto travel time simulation scenario, existing auto travel times between the towns are multiplied by a set of factors between 0.96 and 0.8 , in 0.04 
Table 6: National commuting model explaining work city choice.

\begin{tabular}{|c|c|c|c|c|}
\hline \multicolumn{5}{|l|}{ Model Fit Summary } \\
\hline Number of Records & \multicolumn{4}{|c|}{38630} \\
\hline Number of Alternatives & \multicolumn{4}{|c|}{101} \\
\hline Log Likelihood & \multicolumn{4}{|c|}{-63639} \\
\hline Likelihood Ratio (R) & \multirow{2}{*}{\multicolumn{4}{|c|}{$\begin{array}{c}229287 \\
0.643\end{array}$}} \\
\hline Pseudo $R^{2}$ & & & & \\
\hline Parameter & Estimate & SE & t Value & $\operatorname{Pr}>|t|$ \\
\hline Composite Util. Index Differentials & 1.9765 & 0.0138 & 142.96 & $<0.0001$ \\
\hline Monthly Wage Differentials (NIS) & 0.000466 & 0.000016 & 29.12 & $<0.0001$ \\
\hline Population Differentials & $6.1269 E-06$ & $6.35 E-08$ & 96.49 & $<0.0001$ \\
\hline $\begin{array}{l}\text { Apartment Price (NIS) per } \mathrm{m}^{2} \\
\text { Differentials }\end{array}$ & 0.0000124 & $4.213 E-06$ & 2.94 & 0.0033 \\
\hline $\begin{array}{l}\text { Work in Beersheba Dummy } \times \text { Dist. } \\
(\mathrm{km})\end{array}$ & 0.025 & 0.001649 & 15.17 & $<0.0001$ \\
\hline Work in Haifa Dummy $\times$ Dist. $(\mathrm{km})$ & 0.0272 & 0.000897 & 30.3 & $<0.0001$ \\
\hline $\begin{array}{l}\text { Work in Tel Aviv Dummy × Dist. } \\
(\mathrm{km})\end{array}$ & 0.0269 & 0.000691 & 39 & $<0.0001$ \\
\hline $\begin{array}{l}\text { Work in Ramat Gan Dummy × } \\
\text { Dist. }(\mathrm{km})\end{array}$ & 0.0228 & 0.001202 & 18.94 & $<0.0001$ \\
\hline Small City Dummy $1(<3000)$ & -1.8622 & 0.1018 & -18.3 & $<0.0001$ \\
\hline Small City Dummy 2 (3000-6000) & -1.5705 & 0.0582 & -27 & $<0.0001$ \\
\hline Small City Dummy 3 (6001-10000) & -0.8613 & 0.0403 & -21.4 & $<0.0001$ \\
\hline $\begin{array}{l}\text { Small City Dummy } 4 \\
(10000-15000)\end{array}$ & -0.2822 & 0.0611 & -4.62 & $<0.0001$ \\
\hline $\begin{array}{l}\text { Work and Reside in Same City } \\
\text { Dummy }\end{array}$ & 1.7315 & 0.0155 & 111.58 & $<0.0001$ \\
\hline
\end{tabular}

increments, reflecting an improvement of 4-20 percent in auto travel time throughout the nation. In the rail scenario, the missing train travel times in peripheral town ${ }^{2}$ were replaced by new representative times (slightly lower than auto travel times between the towns) to mimic the introduction of rail service to these towns. The towns included in the rail introduction scenario are Sderot, Netivot, Ofaqim, and four other northern peripheral towns. Beersheba is the only southern city currently linked to the national rail system. In this paper, only selected simulation results pertaining to the study area are presented, although the effect of transport improvements on labor and income shifts can be forecasted for each of the 101 cities belonging to the closed system set.

Table 7 presents employment estimates (number of offered jobs) for the base sce-

\footnotetext{
2 In the calibration stage, train travel times in cities not connected to the national rail system were set to a very high number, to reflect extremely high spatial friction for this particular mode.
} 
nario and for the two simulation scenarios. It is important to note that the basescenario estimates are lower than the census estimates (presented in Table 1) because the base-scenario estimates refer to the data in the closed city set.

Table 7: Number of jobs at destination.

\begin{tabular}{lrrr}
\hline City & Base Scenario & $\begin{array}{r}\text { 20\% Improvement in } \\
\text { Auto Travel Time }\end{array}$ & $\begin{array}{r}\text { Introduction of Rail } \\
\text { Link }\end{array}$ \\
\hline Sderot & 2556 & 2347 & 2606 \\
Ofaqim & 2432 & 2324 & 2417 \\
Netivot & 1744 & 1635 & 1858 \\
Arad & 3648 & 3443 & 3633 \\
Beersheba & 34027 & 33530 & 33954 \\
Tel Aviv & 186259 & 193566 & 186665 \\
\hline
\end{tabular}

As can be seen from the table, in the auto travel time improvement scenario, the number of jobs in the southern towns is reduced by four percent (Ofaqim) to eight percent (Sderot) compared to the base scenario. In the southern district capital of Beersheba, employment drops by 1.5 percent as out-commuting flows increase-primarily to the southern peripheral towns, to the port city of Ashdod, and to various cities in the core area. Employment in Tel Aviv grows by nearly four percent, with the increase primarily attributable to increased commuting from other core cities to Tel Aviv, and not to increased commuting from the southern cities. Labor changes in the railintroduction simulation scenario are less drastic; the most significant change occurs in Netivot, where employment is increased by 6.5 percent.

Figure 4 presents the absolute growth in wages in the southern towns and in Tel Aviv. As can be seen from the graph, linking the southern towns of Sderot, Netivot and Ofaqim to the national rail system may result in a moderate increase in the average wage in these towns. Wages in Sderot are expected to increase by 6.5 percent (210 NIS), in Ofaqim by 4.7 percent (152 NIS), and in Netivot by 4.4 percent (147 NIS). The auto travel improvement scenario forecasts that a drastic improvement in the highway system (20 percent reduction in travel time) will result in more modest average-wage increases in these cities: 4.7 percent (152 NIS) in Sderot; 2.5 percent (83 NIS) in Netivot; and 1.7 percent (55 NIS) in Ofaqim.

The city of Arad, which is not included in the Israel Railways expansion plan, is expected to benefit only from the highway improvement scenario, where the average wage in the city is expected to rise by nearly four percent (149 NIS). The primary reason for this result is the proximity of the town to Jerusalem, where higher wages are offered. The core city of Tel Aviv is barely affected by transport improvements. A very small wage increase (33 NIS) is expected in Tel Aviv in the highway-improvement 
scenario; this is primarily due to a minor change in the commuting pattern of Tel Aviv residents of lower economic status, who leave their jobs in Tel Aviv to work in other core cities that offer higher wages.

The welfare changes in core and peripheral cities are not symmetrical; transport improvements have a much greater effect on welfare in small cities than in large ones like Tel Aviv and Beersheba. This is mainly due to the fact that small cities offer their residents an inferior set of amenities (e.g. lower wages and a smaller labor supply), increasing the probability that residents will search for work elsewhere.

Figure 4: Absolute wage growth in southern towns and Tel Aviv as function of transport improvements.

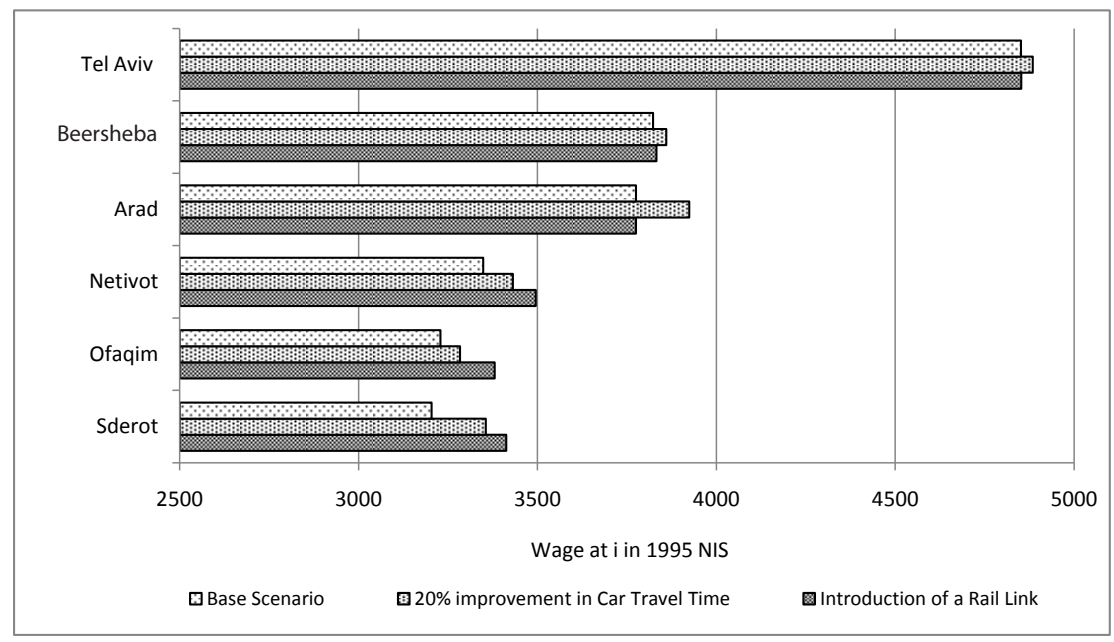

Figure 5 presents direct arc elasticities of wages with respect to changes in auto travel time. As can be clearly seen from this figure, wage elasticities are inelastic (> 1 ) and positive. The city of Sderot, which is the poorest (in terms of wage at $i$ ) of the southern cities, exhibits the highest wage elasticities (0.18-0.24). This result is explained by the fact that Sderot is the closest amongst the southern cities to the core region, so even a relatively small reduction in auto travel time significantly increases the utility of working in core towns for Sderot residents. Beersheba, the largest city in the Near Negev, is much less sensitive than the smaller southern towns to auto travel time changes. This is mainly due to the relatively high supply of jobs in Beersheba, the lower wage differentials between Beersheba and core cities, and the larger spatial friction between the two areas.

Figures 6 and 7 present, respectively, inter-regional and intra-regional wage ratios between southern towns and core cities, and between these towns and Beersheba. Pro- 
Figure 5: Direct arc elasticity of wages with respect to change in auto travel time.

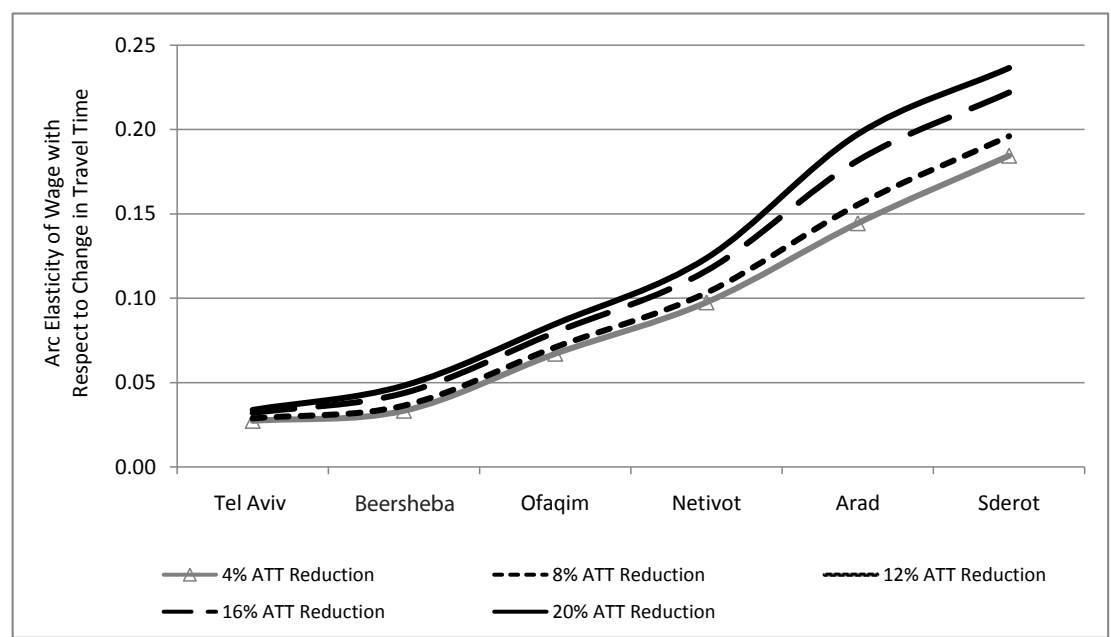

jected wages of the southern cities were divided by the weighted average wages of the two metropolitan areas to produce these wage ratios. As can be seen from the two graphs, the reduction of auto travel time by 20 percent throughout the country is projected to decrease the inter-regional wage ratio between Sderot and core cities by two percent, and between Arad and these cities by 1.6 percent.

The wage ratio between Beersheba and core cities is expected to widen by 0.6 percent under the highway-improvement scenario; the projections of the rail-introduction scenario are much higher. Linking the southern peripheral towns of Sderot, Ofaqim and Netivot to the national rail system is expected to draw them closer to the core cities' average by 4.2, 3.1 and three percent, respectively. No notable change is expected in Beersheba, Tel Aviv (already linked to the rail system) and Arad (not included in the rail expansion plan). These simulation results support the conceptual framework and the research hypothesis presented in the beginning of the paper stating that transport improvements lead to the alleviation of wage disparities (convergence) between core and periphery. 
Figure 6: Inter-regional wage ratios of Beersheba metro towns to core cities.

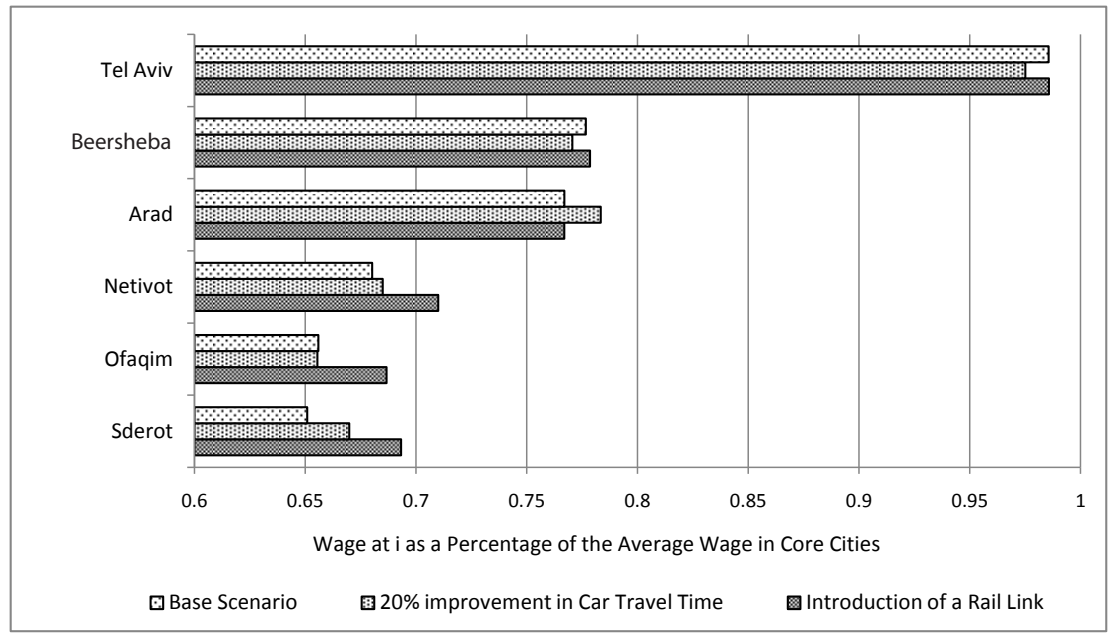

Figure 7: Intra-regional wage ratios of Beersheba metro towns and Beersheba (average wage in Beersheba =1).

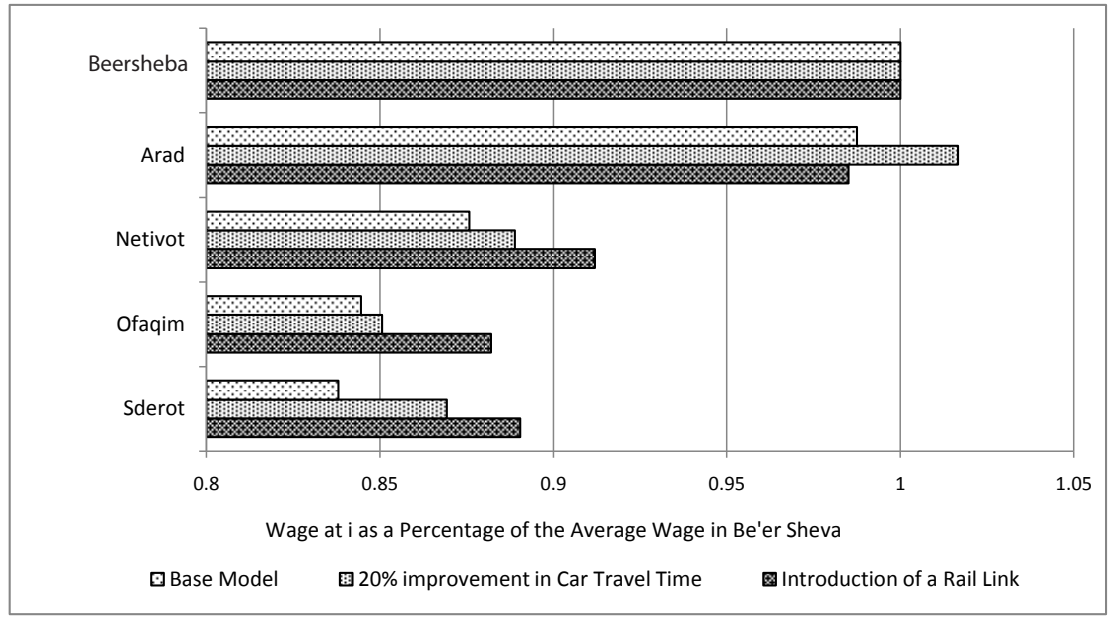

\section{Conclusions}

This paper developed an analytical framework and estimated discrete choice models in order to investigate the impact of transportation improvements on the economic 
equity of cities within a core-periphery structure. Simulation results which pertain to the Core-South disparities in Israel confirm our hypothesis regarding a positive and significant relationship between diminishing spatial friction and enhanced economic welfare. The empirical evidence suggests that transportation improvements, especially in the form of linking underserved cities to the national rail system, could contribute to the redistribution of economic welfare (income transfer) from the affluent core to the poorer periphery.

The value of this study for practitioner-related analyses is twofold. First, it provides planners with a mechanism that enables them to predict workplace choice and estimate the welfare impacts of specific transportation improvements at a spatially detailed level. Second, the research can be beneficial to transportation modelers, since it supplies fresh insights regarding the endogenous impact of wage or individual income on the demand side of commuting trips. The results emphasize the importance of wage differentials in determining the distribution of commuting trips.

The models developed in this paper focused on the equity impacts of transportation improvements. To fully reflect the welfare implications of transportation improvements, the willingness of firms to pay for labor services must be taken into account. Further research will address this issue by focusing on efficiency implications-specifically, by developing a model for estimating the demand side of the labor market. The inclusion of a demand model will enable the modeling of a general equilibrium framework that equalizes the supply and demand sides of the labor market in terms of wages and employment.

Data constraints at the national level did not allow us to compute the impact of transport costs on economic equity indicators. We recognize the importance of this parameter, and future research should address it. This paper has concentrated only on the short-term impacts of transport improvements. It is important to acknowledge that transport improvements may also lead to long-term welfare economic impacts, such as the relocation of firms and businesses. These land-use changes could affect land prices in central and peripheral locations. This important issue should be also addressed in continuing research focusing on long-term impacts.

The models developed in this paper were applied to a specific core-periphery problem. The extremely low employment supply in the southern towns and the one-way and relatively small flow (a few thousands) of laborers from the periphery to the core will not affect the ability of core-region cities to absorb the new commuters. Thus, the methodological approach developed in this paper may be a sufficient framework for addressing the transportation improvement effects on economic equity. Nevertheless, we recognize that further research is needed to fully examine these impacts. The general equilibrium approach suggested above may be a suitable framework for conducting this investigation. 


\section{Acknowledgments}

This research was supported in part by the Sapir Research Grant for Municipal Research. The authors would like to thank the generous support of Mifal Ha'payis for making this research possible. The comments of four anonymous referees are greatly appreciated.

\section{References}

A.B. Plan Ltd. 2004. A Comparative Economical Evaluation of Future Rail Lines. Report prepared for the Israel Ministry of Transport [in Hebrew].

Allen, B. 1984. Trip distribution using composite impedance. Transportation Research Record 944: 118-127.

Aschauer, D.A. 1989. Is public expenditure productive? Journal of Monetary Economics 23: 177-200.

Banister, D., and J. Berechman 2001. Transport investment and the promotion of economic growth. Journal of Transport Geography 9: 209-218.

Banister, D., and N. Lichfield 1995. The key issues in transport and urban development. In: Transport and Urban Development, ed. D. Banister: 1-16. London: E \& FN Spon.

Baxter, M., and G. Ewing 1981. Models of recreational trip distribution. Regional Studies 15: 327-344.

Bekhor, S., and J.N. Prashker 2007. GEV-based destination choice models that account for unobserved similarities among alternatives. Transportation Research $B$ 42 (3): 243-262.

Ben-Akiva, M.E., and S.R. Lerman 1985. Discrete Choice Analysis: Theory and Application to Travel Demand. Cambridge, Mass: MIT Press.

De Jong, G.F., and J.T. Fawcett 1981. Multidisciplinary frameworks and models of migration decision making. In: Migration Decision Making: Multidisciplinary Approaches to Microlevel Studies in Developed and Developing Countries, eds. G.F. De Jong and R. W. Gardner, 13-58. New York: Pergamon Pres.

Dobbs, L. 2005. Wedded to the car: Women, employment and the importance of private transport. Transport Policy 12: 266-278.

Fotheringham, A., and M. O'Kelly 1989. Spatial Interaction Models: Formulations and Applications. Boston: Kluwer.

Fox, W.F., and S. Porca 2001. Investing in rural infrastructure. International Regional Science Review 24: 103-133.

Fritsch, B., and R. Prud'homme 1995. Measuring the contribution of road infrastructure to economic development in France. In: Econometrics of Major Transport 
Infrastructures, eds. E. Quinet and R. Vickerman, 45-67. London: Macmillan Press.

Fujita, M., and T. Mori 1996. The role of ports in making of major cities: Self agglomeration and hub effect. Journal of Development Economics 49: 93-120.

Garrison, W. 1994. Transportation, Innovation and Development. University of California: Berkeley Institute for Transportation Studies.

Gat, D. 2004. On getting closer, becoming more affluent and more equal: An essay on the synergy of proximity. Haifa: Center for Regional and Urban Studies, Technion Israel Institute of Technology. [Working paper].

Guiliano, G. 1979. Public transportation and the travel needs of women. Traffic Quarterly 33: 607-615.

Hanson, S., and G. Pratt 1990. Geographic perspectives on the occupational segregation of women. National Geographic Research 6: 376-399.

Hazans, M. 2004. Does commuting reduce wage disparities? Growth and Change 35: 360-390.

Jia, W., and M. Wachs 1998. Parking and affordable housing. Access 13: 22-25.

Justman, M., and A. Spivak 2004. Socioeconomic dynamics of local authorities in Israel. Israel Economic Review 2: 1-27.

Kuznets, S. 1955. Economic growth and income inequality. American Economic Review 45: 1-28.

Landis, J. 1995. Imagining land use futures: Applying the California urban futures model. Journal of the American Planning Association 61: 438-457.

Lansing, J.B., and E. Mueller 1967. Personal economic incentives and mobility. In: The geographic mobility of labor eds. J.B. Lansing and E. Mueller. Ann Arbor: Survey Research Center, University of Michigan.

Madden, J.F. 1981. Why women work closer to home. Urban Studies 18: 181-194.

Martinez, F.J. 1992. The bid choice land-use model-An integrated economic framework. Environment and Planning A 24: 871-885.

Massey, D.S., A.B. Gross, and K. Shibuya 1994. Migration, segregation, and the geographic concentration of poverty. American Sociological Review 59: 425-445.

Mayhew, L.D., R.W. Gibberd, and H. Hall 1986. Predicting patient flows and hospital case-mix. Environment and Planning A 18: 619-638.

McCormick, B. 1997. Regional unemployment and labour mobility in the UK. European Economic Review 41: 581-589.

Munnell, A. 1990. Why has productivity declined? Productivity and public investment. New England Economic Review, Jan-Feb: 3-22.

Myrdal, G. 1957. Economic theory and under-developed regions. London: Duckworth.

PGL Ltd. 2001. Travel demand forecasting model. Report prepared for NTA, mass transit system for the Tel Aviv Metropolitan Area [in Hebrew]. 
Pickup, L. 1985. Women's travel needs in a period of rising female employment. In: Transportation and mobility in an era of transition, eds. G. Jansen, P. Nijkamp and C. Ruijgrok, 97-113. New York: Elsevier.

Pickup, L., and G. Giuliano 2005. Transport and social exclusion in Europe and the USA. In: Social dimensions of sustainable transport, eds. K. Donaghy, S. Poppelreuter and G. Rudinger, 38-49. Aldershot UK: Ashgate Publishing.

Presman, N., and A. Arnon 2006. Commuting patterns in Israel: 1991-2004. Jerusalem: Research Department, Bank of Israel. Discussion Paper No. 2006.04.

Pucher, J., and J.L. Renne 2003. Socioeconomics of urban travel: Evidence from the 2001 NHTS. Transportation Quarterly 57: 49-77.

Renkow, M., and D. Hoover 2000. Commuting, migration, and rural-urban population dynamics. Journal of Regional Science 40: 261-287.

Rey, S. 2001. Spatial analysis of regional income inequality. San Diego State University, Working Paper.

Rietveld, P. 1989. Infrastructure and regional development. Annals of Regional Science 23: 255-274.

Rosenbloom, S., and E. Burns 1993. Gender differences in commuter travel in Tucson: Implications of the travel demand management programs. Transportation Research Record 1404: 82-90.

Roy, J.R., and J.C. Thill 2004. Spatial interaction modeling. Papers in Regional Science 83: 339-361.

Social Security Institute 2002. Wage and income averages by cities and different economic variables, Jerusalem [in Hebrew].

VandenBerg, G.J., and C. Gorter 1997. Job search and commuting time. Journal of Business \& Economic Statistics 15: 269-281.

Waddell, P. 2000. A behavioral simulation model for metropolitan policy analysis and planning: Residential location and housing market components of UrbanSim. Environment and Planning B 27: 247-263.

Wegener, M., R. Mackett, and D. Simmonds 1991. One city, three models: Comparison of land use/transport policy simulation models for Dortmund. Transport Reviews. 11 (2): 107-129.

Williamson, J.G. 1965. Regional inequality and the process of national development - A description of the patterns. Economic Development and Cultural Change 13: $1-84$.

Yiftachel, O. 2000. Social control, urban planning and ethno-class relations: Mizrahi Jews in Israel's 'development towns'. International Journal of Urban and Regional Research 24: 418-438.

\section{Data Sources}

Israel Central Bureau of Statistics 1995. Census of Population and Housing. 
Israel Central Bureau of Statistics 2001. Local Authorities in Israel. Available online at http://www.cbs.gov.il/publications/local_authorities2005/excel/p_libud.xls.

Israel Ministry of Construction and Housing 2006. Housing Prices by Locality 1997-2006. 